\title{
Etiological Factors of Infective Endocarditis in Children Aged 1 Month to 15 Years Hospitalised in the Paediatric Department of CHU Gabriel Touré of Bamako (Mali)
}

\author{
Maiga Belco*, Sacko Karamoko, Konaté Djéneba, Diakité Abdoul Aziz, Dembélé Adama, \\ Cissé Mohamed Elmouloud, DansoKo Nassira, Traoré Kalilou, Togo Pierre, \\ Doumbia Abdou Karim, Traoré Fousseini, Diakité Fatoumata Léonie, Sidibé Lalla, Maiga Leila, \\ Ahmadou Ibrahim, Coulibaly Oumar, Diall Hawa, Sylla Mariam
}

Department of Pediatrics CHU Gabriel Touré, Bamako, Mali

Email: ^belcosmaiga@yahoo.fr

How to cite this paper: Belco, M., Karamoko, S., Djéneba, K., Aziz, D.A., Adama, D., Elmouloud, C.M., Nassira, D., Kalilou, T., Pierre, T., Karim, D.A., Fousseini, T., Léonie, D.F., Lalla, S., Leila, M., Ibrahim, A., Oumar, C., Hawa, D. and Mariam, S. (2022) Etiological Factors of Infective Endocarditis in Children Aged 1 Month to 15 Years Hospitalised in the Paediatric Department of CHU Gabriel Touré of Bamako (Mali). World Journal of Cardiovascular Surgery, 12, 13-20.

https://doi.org/10.4236/wjcs.2022.122002

Received: January 11, 2022

Accepted: February 25, 2022

Published: February 28, 2022

Copyright $\odot 2022$ by author(s) and Scientific Research Publishing Inc. This work is licensed under the Creative Commons Attribution International License (CC BY 4.0).

http://creativecommons.org/licenses/by/4.0/ (c) (i) Open Access

\begin{abstract}
Introduction: In emerging countries where studies are rarer, the epidemiological profile of infective endocarditis resembles that of developed countries at the beginning of the antibiotic era. There is little data available in Mali on this subject, motivating this study, the aim of which was to study the etiological factors of infective endocarditis in children aged between 1 month and 15 years hospitalised in the paediatric department of the CHU Gabriel Touré. Patients and Methods: We conducted a cross-sectional and descriptive study, which took place from August 2018 to August 2019 (13 months), in children aged between 1 month and 15 years hospitalised in the paediatric department of the Gabriel Touré University Hospital with an ultrasoundconfirmed cardiac disease and a temperature above $38^{\circ} \mathrm{C}$. Results: The hospitalization rate was $0.4 \%$. The average age was 11 months, the sex ratio was 1.35. Respiratory distress (63.6\%) and fever (30.3\%) were the most common reasons for referral. Congenital heart disease (87.9\%) and dyspnoea on feeding $(24.2 \%)$ were the most common medical histories. IVC was the most frequent congenital heart disease $(36.4 \%)$. The mean temperature was $39.1^{\circ} \mathrm{C}$. Blood cultures were taken in 24 patients $(72.7 \%)$ and were positive in $27.3 \%$. Staphylococcus aureus was found in $55.6 \%$ of cases. Trans-thoracic ultrasound found vegetations in 03 cases. According to the modified DUKE criteria, the diagnosis of endocarditis was retained in $27.30 \%$. The evolution was marked by a high case fatality rate $(45.45 \%)$. Conclusion: Endocarditis is an uncommon disease in children with a pulmonary portal of entry and Staphy-
\end{abstract}


lococcus aureus as the main germ. Its mortality remains high.

\section{Keywords}

Infective Endocarditis, Etiological Factors, Pediatrics, Bamako

\section{Introduction}

Infective endocarditis (IE) is an inflammation of the endocardium of microbial origin. It may involve the cardiac valvular endothelium, prosthetic valves and any other intra-cardiac prosthetic material [1]. It is rare in children with 0.78 per 1000 admissions per year [2], but its frequency is not decreasing despite the introduction of new antibiotics [3]. The germs responsible for infective endocarditis have not changed over time. Streptococci and staphylococci are the most common causative organisms [3]. Infective endocarditis in children has been on the increase for several decades, with a prevalence in healthy hearts ranging from 0.42 to 1.35 per 1000 admissions to paediatric wards [4]. In emerging countries, where studies are scarcer, the epidemiological profile resembles that of developed countries at the beginning of the antibiotic era [5]. Infective endocarditis is considered rare in the African literature [6] [7].

Interest in this condition has increased with the considerable development of echocardiographic exploration techniques that allow the detection of increasingly discrete lesions, but also with the contribution of immunological and molecular techniques that have begun to unravel the mystery of microbial infective endocarditis [1].

In Africa south of the Sahara, very few studies have focused on endocarditis. The objectives of this study were: to determine the socio-demographic profile, the hospital frequency, and the short-term outcome of infective endocarditis in children hospitalised in the paediatric department of the Gabriel Touré University Hospital.

\section{Patients and Methods}

We conducted a cross-sectional and descriptive study, which took place from August 2018 to August 2019 (thirteen months), in children aged between 1 month and 15 years hospitalised in the paediatric department of the CHU Gabriel Touré. The Center Hospitalier Universitaire Gabriel TOURE is a third reference hospital, located in commune III of the District of Bamako, capital of the Republic of Mali. Located in the city center it is easily accessible for the majority of the population. It has four (04) main missions: It comprises nine (9) departments including the department of pediatrics. All patients aged between 1 month and 15 years hospitalised and having a confirmed heart disease on ultrasound and a temperature higher than $38^{\circ} \mathrm{C}$ were included, regardless of the origin or the treatment received, with the parents/guardians having given their 
consent. Blood cultures and cardiac ultrasound were systematically requested in all included patients. On admission, we took a temperature reading, questioned the parents, and then carried out a thorough clinical examination of all the patients included in the study in search of an infectious focus. A form was developed for data collection. The variables studied were epidemiological (sex, ethnicity, residence, age, period of admission, history, death, etc.), clinical (questioning, ENT, pulmonary and meningeal signs, etc.) and paraclinical (echo-cardiography, frontal chest X-ray, blood culture, $\mathrm{CBC}$ ) characteristics.

The data were collected in Excel 2016, then inserted into an Epi Info version 7 database for analysis. Quantitative variables were presented as means and categorical variables as \% proportions. The Chi-square test was used for statistical analysis with a significance level of 0.05 . The confidentiality of the data was respected.

\section{Results}

Limit of the study: Mali does not have an adequate technical platform for the surgical management of endocarditis and is responsible for the high mortality of this pathology.

\subsection{Epidemiological Characteristics}

During the study period, we included 33 suspected cases of endocarditis out of 8462 hospitalisations in the paediatric department of the CHU Gabriel Touré, i.e. a hospital frequency of $0.4 \%$. The $1-24$ month age group was the most represented with $84.85 \%$ (Table 1) and the mean age was 11 months with extremes of 2 and 72 months (Table 1 ).

The sex ratio was 1.35 and the majority of patients (90\%) resided in Bamako (Table 1).

Table 1. Socio-demographic characteristics of children seen for acute fever.

\begin{tabular}{ccc}
\hline Features & Numbers $(\mathbf{n}=\mathbf{3 3})$ & $\%$ \\
\hline Age range (months) & 28 & 84.8 \\
\hline $1-24$ & 02 & 06.1 \\
$25-36$ & 03 & 09.1 \\
$37-72$ & 19 & 58 \\
\hline Sex & 14 & 42 \\
\hline Male & 1.35 & \\
Feminine & & 90 \\
Sex ratio & 30 & 10 \\
\hline Residence & 03 & \\
\hline Bamako & & \\
Outside Bamako & 19 & \\
\hline
\end{tabular}




\subsection{Clinical and Paraclinical Characteristics}

On admission the majority of patients had a temperature between $38.5^{\circ} \mathrm{C}$ and $39^{\circ} \mathrm{C}(63.8 \%)$, and the mean temperature was $39.1^{\circ} \mathrm{C}$ with extremes of $38.5^{\circ} \mathrm{C}$ and $40^{\circ} \mathrm{C}$. Respiratory distress with 21 cases (63.6\%) and fever with 10 cases $(30.3 \%)$ were the most frequent referral reasons (Table 2). Personal medical history was dominated by congenital heart disease $(87.9 \%)$ and dyspnoea during feedings $(24.2 \%)$. More than a third of our sample $(36.4 \%)$ had severe acute malnutrition. The physical examination revealed a murmur in all cases, respiratory distress in $93.9 \%$ and crepitus in $57.6 \%$. The pulmonary portal of entry was the most common (57.6\%), and was oral in $9.1 \%$ of patients (Table 2, Table 3 ).

Interventricular communication (IVC) was the most frequent congenital heart disease (36.4\%) (Table 4).

Table 2. Distribution of patients by reason for referral.

\begin{tabular}{ccc}
\hline Reference ground & Number $(\mathbf{N}=33)$ & $(\%)$ \\
\hline Respiratory distress & 21 & 63.6 \\
Fever & 10 & 30.3 \\
Altered general condition & 9 & 27.3 \\
Cough & 2 & 6.1 \\
Rheumatic heart disease & 2 & 6.1 \\
Convulsion & 1 & 3 \\
Abdominal pain & 1 & 3 \\
Endocarditis & 1 & 3 \\
Undernutrition & 1 & 3 \\
\hline
\end{tabular}

Table 3. Distribution of patients by examination at entry.

\begin{tabular}{cccc}
\hline \multirow{2}{*}{ Physical examination } & Number (N: 33) & $(\%)$ \\
\hline \multirow{2}{*}{ Skin examination } & Digital Hippocratism & 6 & 18.2 \\
& Cyanosis & 3 & 9.1 \\
Abdominal & Purpura & 5 & 15.2 \\
examination & Splenomegaly & 11 & 33.3 \\
& Hepatomegaly & 5 & 15.6 \\
ENT examination & Pharyngitis & 7 & 21.2 \\
& Dental Carrie & 3 & 9.1 \\
\hline Examination & Angina & 5 & 15.2 \\
Cardiovascular & Breath & 33 & 100 \\
\hline & Hepato-jugular reflux & 6 & 18.2 \\
\hline Lung examination & Respiratory distress & 31 & 93.9 \\
& Sizzling & 19 & 57.6 \\
\hline
\end{tabular}


Table 4. Distribution of patients according to echocardiogram result.

\begin{tabular}{ccc}
\hline Echo-core result & Number & (\%) \\
\hline Not achieved & 5 & 15.2 \\
Interventricular communication & 9 & $\mathbf{2 7 . 3}$ \\
Atrioventricular communication & 4 & 12.2 \\
Interauricular communication + Expansion of cavities & 3 & 9 \\
Complex Congenital Heart Disease & 3 & 9 \\
Transposition of the great vessels & 2 & 6.1 \\
Mitral insuffisance rheumatic + vegetation & 2 & 6.1 \\
Mitral insuffisance rheumatic + Pericardial detachment & 2 & 6.1 \\
Interventricular communication with vegetation & 1 & 3 \\
Tetralogy of Fallot & 1 & 3 \\
Common artery & 1 & 3 \\
Total & 33 & 100 \\
\hline
\end{tabular}

More than three quarters of the sample had anaemia (78.8\%), leukocytosis was present in $63.6 \%$ of patients and C reactive protein was elevated in $72.72 \%$. Blood cultures were taken in 24 patients (72.7\%) and positive in $27.3 \%$ of cases. The most frequently found germs were: Staphylococcus aureus (55.6\%), Streptococcus pneumoniae (33.3\%) and Klebsiella pneumoniae (11.1\%) (Figure 1). The signs on the frontal chest X-ray were dominated by cardiomegaly associated with hilobasal pneumonia (15.15\%) and isolated cardiomegaly (9.1\%). Transthoracic ultrasound revealed vegetations in 03 cases (9.1\%).

According to the modified DUKE classification, the diagnosis of endocarditis was retained in 9 patients $(27.3 \%)$. The etiological treatment consisted of intravenous administration of amoxicillin/clavulanic acid in $54.54 \%$ of cases. The average duration of treatment was 14 days with an extreme range of 1 to 49 days.

\subsection{Evolutionary Characteristics}

The evolution was marked by the death of 15 patients (45.45\%) (Figure 2).

\section{Discussion}

In our study we recorded a hospital incidence of $0.4 \%$. In Africa data on endocarditis are poor. Yamego et al. [2] and N'Diaye MB [6] recorded a higher frequency with respectively $1.7 \%$ and $1.04 \%$. The reasons for referral are dominated by respiratory distress and fever. Some authors confirm the predominance of respiratory distress [6]. All patients had underlying heart disease, and congenital heart disease was in the majority.

Weli $\mathrm{M}$ et al. [3] found similar results. In developed countries, most infective endocarditis in children complicates congenital heart disease [7]. Yamego et al. [2] recorded the presence of rheumatic heart disease. This situation is common 


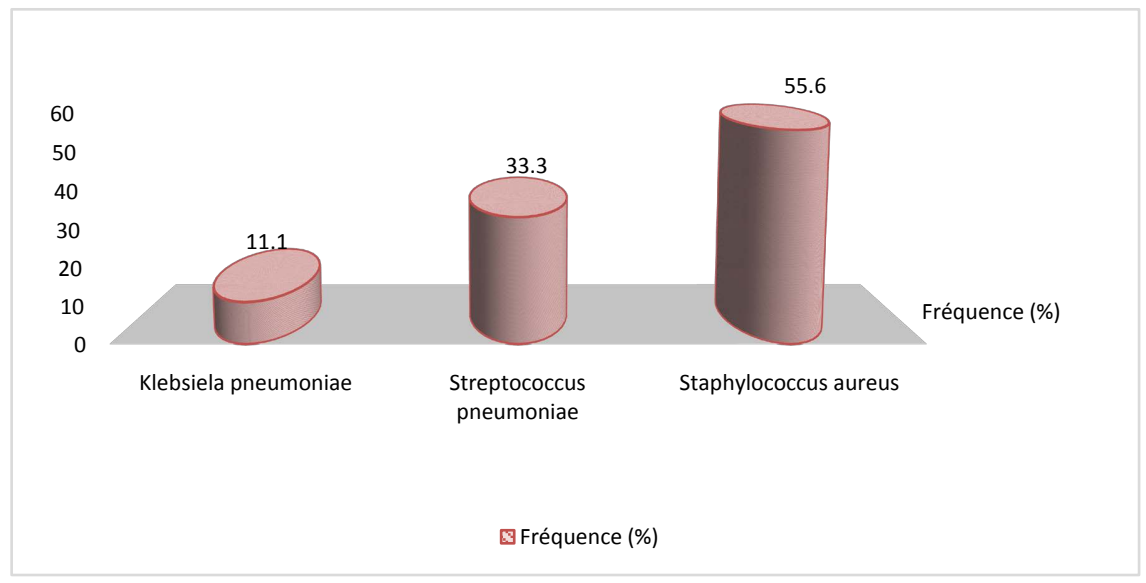

Figure 1. Distribution of patients according to the germ isolated (N: 33).

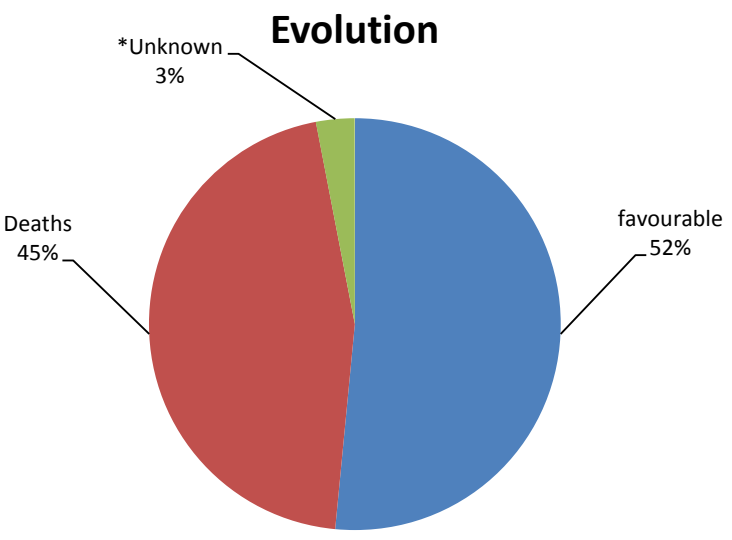

Figure 2. Distribution of hospital developments (N: 33).

${ }^{\star}$ Exit against medical advice.

to developing countries where we observe a regression of rheumatic heart disease and a recrudescence of congenital heart disease secondary to an improvement in diagnostic means contrasting with the low level of the technical platform for better management by surgical or interventional procedures.

Cardiac auscultation is only suggestive when it confirms the appearance of a heart murmur or a change in the intensity of a known murmur. The presence of a murmur is a major criterion of DUKES, often considered a classic clinical sign of infective endocarditis [8]. A murmur was found in all our patients.

The portal of entry is rarely found, it was pulmonary in 19 patients (57.6\%), oral in 3 patients (9.1\%). Yamego et al. [2] and Weli et al. [3] reported a predominance of the oral portal of entry. Infectious entry points are increasingly suspected and identified [9]. Systematic transcardiac ultrasound performed in all patients showed vegetations in $9.1 \%$. This is significantly lower than the results of Weli et al. [3] and Yamego et al. [2] who recorded the presence of vegetations in $97 \%$ and $94.7 \%$.

It should be remembered that a normal cardiac ultrasound does not rule out the diagnosis of infective endocarditis, and it is advisable to repeat the examina- 
tion a few days later if the diagnostic doubt persists [9]. However, in our context, it was only performed once on admission because most of the parents have a modest income. According to the literature, staphylococcus and streptococcus are the most frequent germs of bacterial infective endocarditis.

Our work has shown the same observation. Staphylococcus aureus was found in 55.6\%, Streptococcus pneumoniae in 33.3\%, and Klebsiella pneumoniae in $11.1 \%$. Ferrieri et al. found that streptococcus and staphylococcus were predominant [10]. This finding is shared by Yamego et al. [2].

The presence of a large number of negative blood cultures has been reported by several authors [3] [6]. According to the literature, no germ is identified in 6 to $11 \%$ of infective endocarditis [11] [12]. Indeed, the majority of our patients had received antibiotics before admission to hospital, as they were referred by lower level health facilities. Indeed, antibiotics prescribed unexpectedly and indiscriminately can delay the diagnosis and make it difficult to identify the causative germ.

Delayed diagnosis, unfavourable nutritional status and, above all, inadequate technical facilities for appropriate treatment (lack of surgical/interventional management) could be an explanation for our high mortality.

\section{Conclusion}

Infective endocarditis is a relatively rare condition in our context. Mortality is high. Early detection of congenital heart disease and improvement of the technical platform will help to reduce this very high lethality.

\section{Conflicts of Interest}

The authors declare no conflicts of interest regarding the publication of this paper.

\section{References}

[1] Moreillon, P. and Que, Y.-A. (2009) Infective Endocarditis. Lancet, 363, 139-149. https://doi.org/10.1016/S0140-6736(03)15266-X

[2] Yameogo, N.V., Kologo, K.J., Yameogo, A.A., Yonaba, C., Millogo, G.R.C., Kissou, S.A., et al. (2014) Infectious Endocarditis in Sub-Saharan African Children, a Cross-Sectional Study about 19 Cases in Ouagadougou, Burkina Faso. Annals of Cardiology and Angiology, 63, 7-10 https://doi.org/10.1016/j.ancard.2013.02.004

[3] Weli, M., Kolsi, R., Abid, D., Maalej, B., Zaghdoud, R., Ben Ameur, S., Elleuch, A., Kammoun, T., Kammoun, S., Gargouri, L. and Mahfoudh, A. (2020) Infective Endocarditis in Children: Retrospective Study of 33 Cases. J.I. M. Sfax, 34, 22-31.

[4] Le Guillou, S., Casalta, J.P., Fraisse, A., Kreitmann, B., Chabrol, B., Dubus, J.C. and Bosdure, E. (2010) Infective Endocarditis on Healthy Heart in Children: Retrospective Study of 11 Cases. Archives de Pediatrie, 17, 1047-1055. https://doi.org/10.1016/j.arcped.2010.03.019

[5] Nibouche, D. (2015) L'endocardite infectieuse; module de cardiologie. Faculté de Médecine d'Alger. p. 31.

https://cours-examens.org/images/An_2015_1/Medecine/Cardio/Alger/Endocardite 
\%20\%20infectieuse\%20Pr\%20D.\%20NIBOUCHE.pdf

[6] Ndiaye, M.B., Diao, M., Kane, A., Bodian, M., Mbaye, A., Dia, M.M., Sarr, M., Kane, A. and Ba, S.A. (2010) Infectious Endocarditis in the Dakar Cardiology Setting: A Descriptive Study about of 39 Cases. Pan African Medical Journal, 7, 1-10. https://doi.org/10.4314/pamj.v7i1.69118

[7] Coward, K., Tucker, N. and Darville, T. (2003) Infective Endocarditis in Arkansan Children from 1990 through 2002. The Pediatric Infectious Disease Journal, 22, 1048-1052. https://doi.org/10.1097/01.inf.0000101186.88472.b5

[8] Li, J.S., Sexton, D.J., Mick, M., et al. (2000) Proposed Modifications to the DUCKE Criteria for the Diagnosis of the Infective Endocarditis. Clinical Infectious Diseases, 30, 633-638. https://doi.org/10.1086/313753

[9] Sochowski, R.A. and Chan, K.L. (1993) Implication of Negative Results on a Monoplane Transesophageal Echocardiographic Study in Patients with Suspected Infective Endocarditis. Journal of the American College of Cardiology, 21, 216-221. https://doi.org/10.1016/0735-1097(93)90739-N

[10] Ferrieri, P., Gewitz, M.H., Gerber, M.A., et al. (2002) Unique Features of Infective Endocarditis in Childhood. Circulation, 105, 2115-2126.

https://doi.org/10.1161/01.CIR.0000013073.22415.90

[11] Delahaye, F., Goulet, V., Lacassin, F., Ecochard, R., Suty-Selton, C., Hoen, B., et al. (1993) Epidemiology of Infective Endocarditis in France in 1991. Arch Mal Coeur, 86, 1801-1806.

[12] Li, W. and Sommerville, J. (1998) Infective Endocarditis in the Grown-Up Congenital Heart (GUCH) Population. European Heart Journal, 19, 166-173.

https://doi.org/10.1053/euhj.1997.0821 